\title{
SÍNDROME DE FOURNIER: UM RELATO DE CASO
}

\section{Hemerson Garcia de Oliveira Silva ${ }^{1}$; Carolina Corrêa Lima ${ }^{2}$; Giselle Pena de Oliveira ${ }^{3}$; Henrique de Souza Rodrigues Fajardo ${ }^{4}$; Alex Loze Rocha ${ }^{5}$; Iago Gama Pimenta Murta ${ }^{6}$; Marcos Vinícius Mendes Barroso ${ }^{7}$;Robson da Silveira ${ }^{8}$}

${ }^{1}$ Medico, Mestre em Ciências Biológicas, Universidade Vale do Rio Doce (UNIVALE), Manhuaçu, MG.

${ }^{2}$ Discente de Medicina, Centro Universitário UNIFACIG (UNIFACIG), Manhuaçu, MG.

${ }^{3}$ Discente de Medicina, Centro Universitário UNIFACIG (UNIFACIG), Manhuaçu, MG.

${ }^{4}$ Médico Residente de Cirurgia Geral, Hospital César Leite (HCL), Manhuaçu, MG.

${ }^{5}$ Médico Residente de Cirurgia Geral, Hospital César Leite (HCL), Manhuaçu, MG.

${ }^{6}$ Médico Residente de Cirurgia Geral, Hospital César Leite (HCL), Manhuaçu, MG.

${ }^{7}$ Médico Residente de Cirurgia Geral, Hospital César Leite (HCL), Manhuaçu, MG

${ }^{8}$ Médico Cirurgião Geral e Urologista, Hospital César Leite (HCL), Manhuaçu, MG.

DOI: $10.47094 /$ ICONRES.2021/18

\begin{abstract}
RESUMO
Introdução: A Síndrome de Fournier é uma fasciíte necrosante que ocorre em região perineal, perianal e genital, gerada por processo infeccioso de microrganismos aeróbios e anaeróbios. Seu índice de mortalidade se mostra elevado, demonstrando a necessidade abordagem imediata. Objetivo: Descrever o caso de um paciente com síndrome de Fournier e os fatores que corroboraram com o estabelecimento do sucesso do tratamento. Metodologia: Trata-se de um relato de caso de um paciente com Grangrena de Fournier, feito na cidade de Manhuaçu, MG, sendo feita uma análise de prontuários. Resultados e Discussão: O paciente deu entrada ao hospital com quadro típico de Síndrome de Fournier. A antibioticoterapia inicial se mostrou ineficiente para conter o processo patológico. Os processos cirúrgicos de desbridamento, colostomia e reconstrução foram aplicados adequadamente para a efetiva terapêutica. Conclusão: A abordagem rápida e eficaz por uma equipe multidisciplinar foi importante para permitir satisfatória recuperação do paciente.
\end{abstract}

PALAVRAS-CHAVES: Gangrena; Antibioticoterapia; Síndrome de Fournier.

ÁREA TEMÁTICA: Clínico - Hospitalar 


\section{INTRODUÇÃO}

A Síndrome ou Gangrena de Fournier, é uma fasciíte necrosante considerada rara, que acomete a

região perineal, perianal e genital. É ocasionada por microrganismos aeróbicos e aneróbicos por meio de um processo infeccioso, o qual, dependendo de uma abordagem terapêutica ineficaz, pode irradiar para a parede do abdômen, membros inferiores, membros superiores e retroperitônio (AZEVEDO, 2016).

A síndrome tende a afetar predominantemente pacientes do sexo masculino, numa proporção aproximada de 10 casos do sexo masculino para 1 do sexo feminino (CARDOSO, FÉRES, 2007). A idade dos pacientes acometidos está em torno da $3^{\mathrm{a}}$ a $6^{\mathrm{a}}$ décadas de vida, tendo como fatores de risco o diabetes mellitus, hipertensão arterial, AIDS, sarampo, obesidade, alcoolismo, tabagismo, desnutrição, imunossupressão, infecções perianais e no trato urinário (DORNELAS, 2012)

O índice de mortalidade para a síndrome se mostra elevado, alcançando em certos estudos $30 \%$ a 50\% dos pacientes (HOFFMAN, 2009). Nesse sentido, a maioria dos casos de síndrome de Fournier é apresentada como emergência cirúrgica, necessitando de abordagem médica imediata, com a administração de antibióticos de amplo espectro e procedimento cirúrgico, a partir da remoção do tecido necrótico por meio do desbridamento e de curativos que permitam a reconstrução do tecido desvitalizado.

O presente trabalho tem como objetivo descrever um relato de caso de um paciente com a síndrome de Fournier, estabelecendo a importância de sua abordagem farmacêutica e cirúrgica rápida e eficaz, a fim de se estabelecer o sucesso do tratamento.

\section{METODOLOGIA}

Trata-se de um relato de caso de um paciente idoso internado em hospital no município de Manhuaçu, Minais Gerais em julho de 2019 com o quadro de síndrome de Fournier. O paciente assinou voluntariamente o Termo de Consentimento Livre e Esclarecido (TCLE) conforme padrão usado pelo COREME do Hospital César Leite, após esclarecimentos dos objetivos do estudo. Foi feita a sua análise de prontuários, baseando sua história clínica e conduta médica em literaturas recentes sobre a Síndrome de Fournier.

\section{RESULTADOS E DISCUSSÕES}

Paciente V.A., 67 anos, sexo masculino, sem comorbidades, deu entrada ao Hospital César Leite, no município de Manhuaçu, em Minais Gerais, no dia 04 de julho de 2019, com um possível abscesso em região glútea bilateral, relatando um quadro de febre, hiperemia e edema que evoluiu em 
cerca 20 dias. Foi iniciada como antibioticoterapia a Ceftriaxona e o Metronidazol. Na mesma data, foi realizado o primeiro procedimento cirúrgico de desbridamento profundo, com a coleta de material para cultura e antibiograma. Na data seguinte, iniciou o uso triplo dos antibióticos Clindamicina, Ampicilina e Amicacina sendo associado a curativo com colagenase.

Foi constatado em exame que as proteínas totais eram de 4,8g/dL (VR: 6,0 a 8,0g,dL), a albumina estava em 2,2g/dL(VR: 3,5 a 5,0g/dL) e a globulina em 2,6g/dL (VR: 2,0 a 4,0g/Dl). Por isso no dia 06 de julho, foi iniciada a dieta enteral hiperproteica, com acompanhamento de nutricionista.

Ao notar uma má resposta ao tratamento, a equipe médica fez novo desbridamento cirúrgico sendo identificada uma fístula retal o que levou a confecção da colostomia de proteção no dia 09 de julho. Após dois dias ao procedimento, foi feito novamente o desbridamento, associado à reconstrução de nádega em região perianal.

No dia 13 de julho, o curativo de colagenase foi trocado por creme de ureia, sendo associado a lavagem de ferida com Povidine tópico. Três dias depois com o resultado do exame de cultura denotou presença de bastonetes gram negativo (Escherichia coli) e coco gram positivo, não sendo possível isolar o gram positivo. E do antibiograma, o qual denotou resistência a determinados antibióticos, como Amoxicilina com Clavulanato, Ampicilina, Ceftriaxona e Ciprofloxacino, e demonstrou sensibilidade a outros, como Ceftazidima, Gentamicina, Meropenem e Carbapenem com Monobactam. Dessa forma, trocou-se o esquema de antibiótico triplo por Ceftazidima.

No dia 25 de julho, foi feito um avanço de retalho pela equipe de cirurgia plástica, seguindo por uma boa evolução e permitindo alta hospitalar do paciente no dia 02 de agosto de 2019. A colostomia foi mantida até o dia 30 de setembro de 2020, data essa em que também foi feita, sem intercorrências, a reconstrução de ferida do paciente.

O paciente do caso apresenta história típica de acometimento pela síndrome de Fournier, uma vez que se trata de um paciente do sexo masculino, com a idade dentro do que é mais amplamente constatado pela epidemiologia. Tendo em vista que o tempo de internação do paciente foi de 29 dias, esse dado entra de acordo, ainda que se mostre ligeiramente maior, com a taxa média de permanência de 26,1 dias dos pacientes acometidos pela gangrena (ABREU, 2014).

A causa dessa síndrome, na maioria das vezes, é uma infecção anorretal, que está frequentemente associada a abscessos perirretais (MELKONIAN,1999), mostrando-se concordante com o caso relatado. Entretanto, o que surpreendeu a equipe que o atendeu, foi que o paciente não havia comorbidades como fatores de risco, os quais são abordados extensamente na literatura e que corroboram com o desenvolvimento da doença.

Os microrganismos com maior prevalência na síndrome de Fournier são os aeróbios gram negativos, como a Escherichia coli e Klebsiella pneumoniae, os gram positivos Staphylococcus aureus, S. epidermidis, Streptococcus viridans e $S$. fecalis, os anaeróbios Bacteróides fragilis, $B$. melaninogenicus, cocos Gram positivos e Clostridium species. (AZEVEDO, 2016). Nesse sentido, o resultado do exame de cultura do paciente foi ao encontro do que se é comumente identificado. A 
antibioticoterapia empregada durante o período de tratamento do paciente parece ter tido influência direta na evolução da terapêutica do caso apresentado. A abordagem inicial com a Ceftriaxona e Metronidazol e, posteriormente, com o esquema triplo mostrou-se ineficiente para conter o processo patológico desencadeado pelos microrganismos que o originou. Após o resultado do antibiograma, foi possível estabelecer uma antibioticoterapia guiada pela sensibilidade apresentada, permitindo uma boa resposta e evolução do paciente, o que anteriormente não acontecia, demonstrando o quanto a morosidade do exame repercute negativamente na progressão da doença.

O tratamento cirúrgico da gangrena de Fournier, assim como foi feito no caso apresentado, consiste em desbridamento do tecido necrosado, a fim de se remover todo tecido lesado que possa impedir a ação do antibiótico (CARDOSO, 2007). Como ocorreu com o paciente, a colostomia também é indicada nas situações que facilitam a contaminação fecal. O cuidado com a ferida também foi feito adequadamente, uma vez que curativos a base de colagenase também são preconizados, bem como o uso de antimicrobiano tópico (CANDELARIA, 2009). Os métodos de reconstrução empregados pela equipe de cirurgia plástica ao paciente desse relato foram feitos visando minimizar as deformidades, nesse sentido, permitindo um bom resultado estético.

\section{CONCLUSÃO}

Apesar da demora na resposta para uma boa evolução do paciente apresentado, nota-se que a equipe de atendimento concluiu com efetividade a sua abordagem, demonstrando a importância do trabalho multidisciplinar direcionado às individualidades apontadas diante do seguimento do caso. As medidas adotadas pela equipe, tais como o desbridamento, a dieta nutricional hiperproteica, a antibioticoterapia ampla, a colostomia e a reconstrução foram satisfatórias para debelar a infecção e permitir a retomada da qualidade de vida do paciente.

\section{PRINCIPAIS REFERÊNCIAS}

ABREU, Rone Antônio Alves de et al. Síndrome de Fournier: estudo de 32 pacientes - do diagnóstico à reconstrução. Revista Ged: Gastroenterologia Endoscopia Digestiva, São Paulo, v. 33 , n. 2, p.45-51, 2014.

AZEVEDO, Cassius Clay S. F. Azevedo et al. Síndrome de Fournier: um artigo de revisão. Connection Line: Revista Eletrônica do UNIVAG, Várzea Grande, v. 15, n. 1, p.70-80, 2016.

CANDELARIA, Paulo de Azeredo Passos et al. Síndrome de Fournier: análise dos fatores de mortalidade. Rev bras. colo-proctol. Rio de Janeiro, v. 29, n. 2, p. 197-202, 2009.

CARDOSO, João B.; FÉRES, Omar. Gangrena de Fournier. Medicina (ribeirão Preto), Ribeirão Preto, v. 40, n. 4, p.493-499, out./dez. 2007. 
DORNELAS, Marilho Tadeu et al. Síndrome de Fournier: 10 anos de avaliação. Rev. Bras. Cir. Plás., v. 27, 2012.

HOFFMAN, Arthur Leopoldo et. al. Síndrome de Fournier: Relato de caso. Arquivos Catarinenses de Medicina, v. 38, suplemento 01, 2009.

MELKONIAN, E. T.; VILLAR, V.M.; CAMPAÑA, G.V. et al. Gangrena de Fournier. Revista Chilena Cirurgia, 1999. 